\title{
Identifying and Ranking Dangerous Road Segments a Case of Hawassa-Shashemene-Bulbula Two-Lane Two-Way Rural Highway, Ethiopia
}

\author{
Mandefro Terefe Abebe', Moltot Zewdie Belayneh² \\ ${ }^{1}$ Road and Transport Engineering, School of Civil Engineering, Hawassa University, Hawassa, Ethiopia \\ ${ }^{2}$ Hydraulic Engineering, School of Water Resources Engineering, Hawassa University, Hawassa, Ethiopia \\ Email: mandefroterefe@yahoo.com, hiot2006@gmail.com
}

How to cite this paper: Abebe, M.T. and Belayneh, M.Z. (2018) Identifying and Ranking Dangerous Road Segments a Case of Hawassa-Shashemene-Bulbula Two-Lane Two-Way Rural Highway, Ethiopia. Journal of Transportation Technologies, 8, 151-174. https://doi.org/10.4236/jtts.2018.83009

Received: December 22, 2017

Accepted: May 13, 2018

Published: May 16, 2018

Copyright $\odot 2018$ by authors and Scientific Research Publishing Inc. This work is licensed under the Creative Commons Attribution International License (CC BY 4.0).

http://creativecommons.org/licenses/by/4.0/

(c) (i) Open Access

\begin{abstract}
According to the study made by United Nation Economic Commission for Africa, Ethiopia stands as one of the worst countries with respect to road safety performance in terms of traffic accident fatalities per 10,000 vehicles (i.e. 95 in 2007/8). Road safety generally depends on humans, vehicles, and highway conditions. These factors influence road safety separately or in combination. One of the basic means to improve road safety is to reduce hazardous conditions of roads. The main objective of this study is to identify and rank hazardous locations and propose appropriate simple and inexpensive countermeasures along Hawassa-Shashemene-Bulbula main two-lane rural road. Accordingly, the road and traffic data were collected from field investigation and Ethiopian Road Authority and accident data were gathered from police stations. Then, the study road equally divided into short sections of 1.5 $\mathrm{km}$ and traffic volume and accident frequencies assigned for each road site to predict theoretical frequencies of accident. Empirical Bayes method and Safety Performance Function have been used to estimate an index known as Potential for Safety Improvement (PSI) for each site of the study area to identify and rank road sites. The result showed that out of 43 road segments 22 of them were identified as dangerous road segments. Moreover, based on further criterion established for screening the ranked road sections 8 road segments were found the most dangerous road segments as they have contributed $76 \%$ of total PSI values. The degree of haphazardness of a given road segment in the study area has directly associated with the availability of risk indicating road and traffic factors. Finally, it recommends that regulatory body of road safety in the study area should give high priority and immediate response for the improvement of most dangerous road segments.
\end{abstract}




\section{Keywords}

Dangerous Road Segment, Empirical Bayes Estimate, Safety Performance Function, Potential for Safety Improvement, Countermeasures

\section{Introduction}

The main purpose of transportation system is to provide the efficient and safe movement of passenger and freight from one place to another. However, the rising number of road accidents created serious social problem resulting in loss of lives and property. In developing countries like Ethiopia traffic accident rate has been still quite high [1] [2]. Therefore, the issue of road safety is a major concern in transportation engineering a country like Ethiopia. According to the World Health Organization report [3], road crashes were the leading cause of death worldwide for children and young people. About 1.25 million people died in 2013 and 50 million injured annually worldwide [3] [4]. More than $85 \%$ of these casualties occurred in low and middle-income countries. Over $90 \%$ of the world's fatalities on the roads occurred in low and middle income countries, which have only $54 \%$ of the world's registered vehicles and these countries contribute $82 \%$ of world's population [4].

A study made in Ethiopia indicated that one of the world's worst accident record of 170 fatalities per 10,000 vehicles occurred in 1994/5 [1] [5]. However, traffic accident death rate per 10,000 motor vehicles was showing a decreasing trend and had reached 95 in 2007/8 from 145 in 2003/4 [1]. The study also indicated the recent phenomenon of decreasing trend of death rates per 10,000 vehicles in the country could not be due to absolute decreases in fatalities and the total road traffic accidents but it was due to the increasing effects of the number of traffic and other exposers. It is also confirmed from the analysis of eight years (2007/8 to 2014/15) accident, traffic and road data obtained from Federal Police Commission (FPC), Federal Transport Authority (FTA) and Ethiopian Road Authority (ERA) respectively. Accordingly, even though traffic accident death per 10,000 vehicles decreased from 111 in 2007/8 in to 65 in 2014/15, the average annual number of total accidents and fatalities increased by $12.2 \%$ and $9.6 \%$ respectively, while the registered vehicles and road network in the country over the past eight years (2008/09 to 2014/15) on average annually increased by 17 and $14 \%$ respectively. The figure showed that there was an unbalanced increment of number of vehicles and fatalities, which resulted in decreasing trend of annual fatality per ten thousand vehicles, over the last few decades.

In contrast to the inverse relationship between fatality rate per 10,000 vehicles and number of vehicles as stated in the above paragraph, exposure to traffic accidents increased due to rapid motorization (without appropriate regulation), rapid population growth, and increased road network coupled with poor attitude and safety culture of road users in Ethiopia [1]. This is also confirmed in the 
above paragraph that the increased number of total accidents and fatalities during eight years period were directly related with the increased effect of registered vehicles and road network in the country. As described in [2], in response to the developing road safety problem in Ethiopia, ERA established specialist traffic engineering and road safety unit, namely Environmental Monitoring and Road Safety Branch (EMRSB), which have responsibility for safe operation of the road network. Even though EMRSB and other stakeholders are conducting some limited activities such as road safety audit and black spot identification task to address road safety problem, it is insufficient by any standard relative to the worsening situation. Hence, it makes necessitate paying more attention to improve the road safety and serious measures should be taken timely because the country is losing tremendous lives and properties.

Although the road traffic accident problems were common across country, two geographical zones can be singled out as the most accidents prone area [1] [2] [6] [7]. These zones are large urban centers like Addis Ababa and highly trafficked major road corridors such as Addis Ababa-Adama, Modjo-Hawassa and similar other main roads in the country. ERA safety audit manual [2] also confirms that the recent road safety problem in Ethiopia was due to improved road network and consequently increasing traffic volume and higher speed coupled with lack of road safety experience and technical skills and poor coordination of the main stakeholders across the country. Despite these facts, insignificant safety studies were carried out in the country and most of these studies were concentrated in the capital city, Addis Ababa.

The main focus of this study is to identify excess accident accumulation site and rank to provide a priority list of sites to be treated according to their potential for safety development and to utilize the limited funds as effectively as possible. It also identifies the major contributing road and traffic factors along the most dangerous road segments and provides simple and inexpensive solutions. In addition to this, it tries to fill the gap of knowledge by using state of the art approaches called potential for safety improvement (PSI), which integrate risk factors associating to the influence of road, traffic related factors and historical accident data to identify dangerous road segments instead of using only historical accidents. Accordingly, the findings of this study will be useful for further implementation of the road safety measures and a baseline of similar studies in the country. Moreover, the identification of hazardous sites by using PSI method, which considers the random nature of accidents and regression-to-the-mean bias, instead of other simple methods is important so as to avoid wasting of resources due to treating the site that are wrongly identified as unsafe site and leaving the truly hazardous sites untreated.

This study document provides a report on the research conducted over the period of September 2012/13 to August 2014/15 in Ethiopia. The scope of the study is limited to Hawassa-Shashemene-Bulbula two-lane rural highway with total length of $64.5 \mathrm{~km}$. 
Various methods are available to identify and rank hazardous site, where the three common black spots or section definitions are numerical, statistical, and model-based [8]. The numerical definition depends only on the recorded number of accidents to identify dangerous road section that it does refer neither to traffic volume nor to the normal number of accidents, nor does it specify the types of location considered. Instead, a site is ranked based on pre specified limit to accident density, which undoubtedly affected by random variation in accident count and regression-to-the-mean problems [9]. Consequently, the method may mistakenly identify hazardous sites just like those sites that have high accident counts or accident rates rather than the normal level of accidents.

The statistical definition depends on the comparison of the recorded number of accidents to a normal number for similar types of location. In this approach, statistical analysis methods such as Rate Quality Control (RQC) and Potential for Accident Reduction (PAR) methods can be used to identify and select hazardous road sections according to [10] and [11] respectively. However, Maher and Mountain [12] identified the potential limitation of these methods due to inaccuracy in the estimation of expected number of accidents at a site and they stated that also using accident count as ranking criterion might perform as well or better than using PAR method.

The Model-based definition of road accident black spots/sections derived from multivariate accident prediction model [8] [13]. Thus, this method also used to estimate the interaction between road and traffic related factors and accident frequencies by means of regression analysis techniques. Empirical Bayes (EB) estimate is used as a criterion for the purpose of identification and ranking of hazardous sites [13] [14] [15]. Other method known as potential for safety improvement (PSI) can also be used to identify and rank dangerous road segments [14] [16]. This approach is similar to PAR method, except that the EB safety estimate is used instead of accident count. Here, PSI has been defined as the difference between the EB safety estimates and the normal level of accidents for similar sites. Hazardous site defined as a site where the observed number of accidents exceeds the accident prediction by either Poisson model estimate or EB estimate by at least one standard deviation [17]. In conclusion, EB estimate has produced fewer black spot sites than accident prediction by Poisson model. The EB method is considered as the most common state-of-the-art method for estimation of safety of a road and also for identification and ranking of dangerous road segments [8] [9] [13] [16] [18]-[24].

To predict frequency of accidents for similar sites in the reference population, different methods can be used. Hauer [13] suggested the following two methods for estimation of predicted number of accidents and its variance 1) the method of sample moments and 2) the multivariate regression method. When the two methods are compared multivariate regression, method provides estimates of predicted number of accidents for reference sites that match the characteristics of the treated site exactly and a large number of reference sites are not needed for any particular combination of road site characteristics unlike the method of 
sample moment.

Alternatively, HSM [14] provides predictive model or Safety Performance Function (SPF), which was developed for different types facilities including rural two-lane two-way highway. This predictive model was developed to estimate the predicted average crash frequency of an individual site, which is called a performance threshold value of homogenous roadway segment.

\section{Methodology}

\subsection{Description of the Study Area}

Ethiopia comprises a road network totaling about 110,414 km, in 2015 . Since 1997 up to 2015, the average road network growth was 8.5 per cent per year. According to ERA design manual [25], roads in Ethiopia classified according to the function of the road and this functional classification of the road in the country categorized in to five road classes. Furthermore, each class of road further classified by design standards based on the ranges of traffic or AADT and road design elements. The road under investigation included in the highest standard rural two-lane highway functional class in the country and it is called Trunk road (which consist of five design standards from DS1 up to DS5) and specifically categorized in to "DS3" design standard. Since the selected road sections has the same design standard they are considered as a homogenous road segments. The road stretch under study is part of the segment that connects Addis Ababa and Hawass cities and also passes through several small and medium towns (Figure 1). This road section is parts of Trans African Highway, which connects Cairo in Egypt and Hebron in Botswana.

Study area is located in Oromia regional state along Hawassa-Shashemene-Bulbula two-lane two-way rural highway, which is found between $188+500 \mathrm{~km}$ Station near to Bulbula town and $265+000 \mathrm{~km}$ Station near to Hawassa city (Figure 2). Both of these Stations measured with reference to $0+000$ station at the center of Addis Ababa. Of this road stretches only the rural two-lane two-way highway that had not undergone any modification during the period (2012/13-2014/15), for which historical accident data were studied, have been investigated in this study. Accordingly, out of $76.5 \mathrm{~km}$ road stretch only $64.5 \mathrm{~km}$ road segments have been selected for detail investigation. According to Segni [7], even though this road section is very important route in terms of economic and social aspects, it has been accompanied with high accident rate. This indicates that the selected study sites were one of the expected accident-prone locations in the country. Furthermore, the selection of study sites extremely depends on the availability of adequate and reliable data.

\subsection{Data Collection}

\subsubsection{Data Source}

Primary data: obtained by inspecting and measuring road geometry, roadside hazards and delineation, and field reconnaissance survey to observe the characteristics of traffic. 


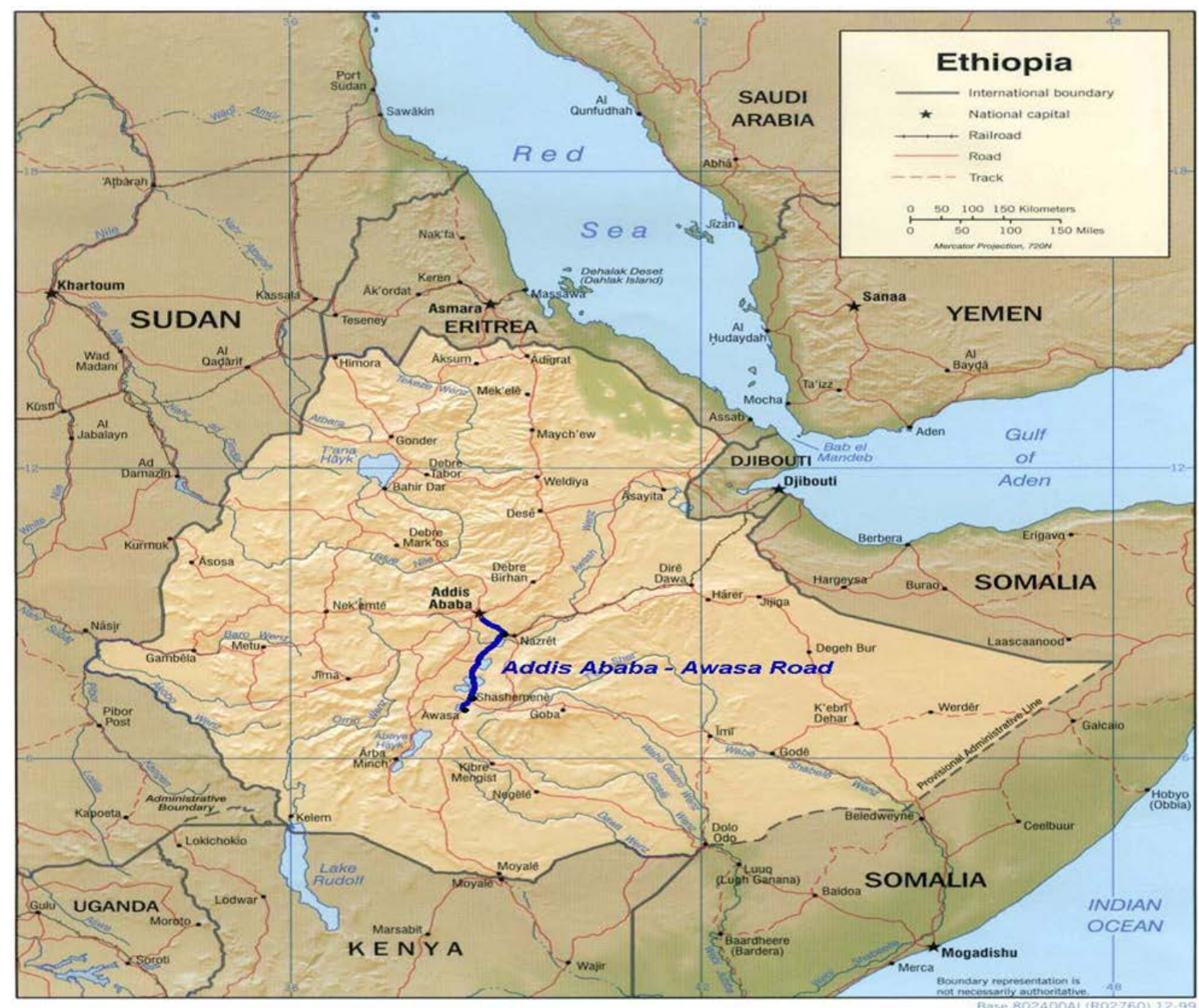

Figure 1. Map of study area corridor (Addis Ababa-Hawassa) trunk road.

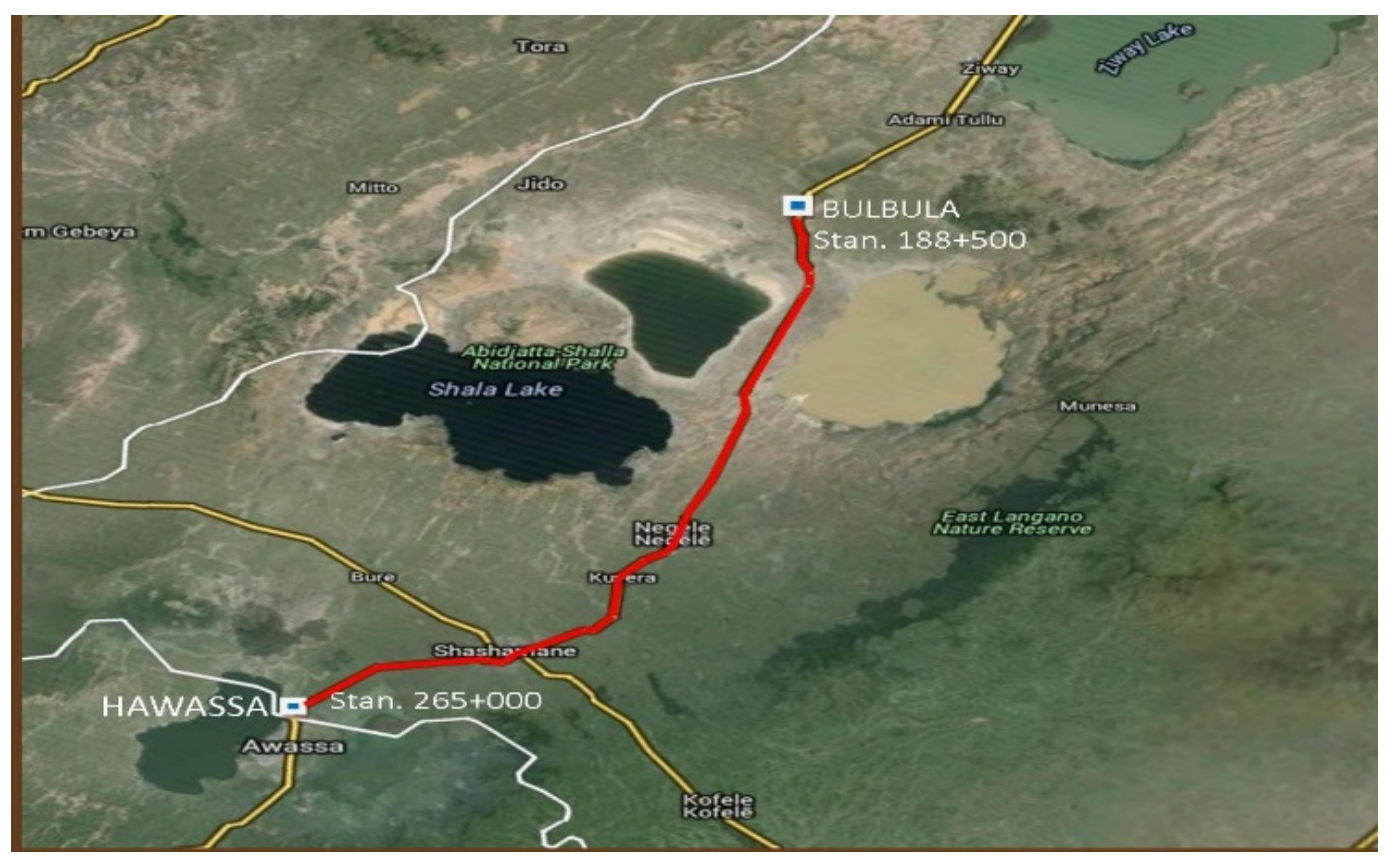

Figure 2. Location map of study area (Source: Google map). 
Secondary data: road crash data obtained from traffic police report, road as built drawing and average Annual Daily Traffic (AADT) collected from Ethiopian Road Authority (ERA).

\subsubsection{Types of Data}

Three types of data have been used in this study namely, road, accident and traffic data.

The road factors being investigated were road segment length, horizontal curvature, vertical grades, cross-sectional elements (e.g. number of lanes, lane width, shoulder width and surfacing), number of minor junction per $\mathrm{km}$, roadside hazard, sidewalks and crosswalks, traffic sign, road surface marking, sight distance and other pertinent data like terrains type, land use, and so on. Drawing of the road plan and profile were obtained from design document at ERA and substantiated through actual measurements and visual inspection along the road sites.

Since the road is homogeneous, the road stretches were equally divided into short sections of $1.5 \mathrm{~km}$ based on kilometer post. Then, for each road segment traffic volumes and accident frequencies have been assigned in order to predict theoretical frequency of accidents for each road site. In total, 43 road sections (total length $=64.5 \mathrm{~km}$ ) of two-lane two-way rural highway were considered in this study.

Traffic accidents data of three years (2012/13-2014/15), were collected from accident booklets compiled by traffic police offices. The data were organized using a designed format which include: date, time of accident, vehicle type and ownership, driver sex, age and education, weather, road, and illumination condition, accident type, degree of severity, and number of victims (driver, passenger, and pedestrian) and their sex, age, severity; and location of accident. Since the location of accidents were registered broadly by the name of surrounding land use such as name of village, School, Mosque, Church, River, or "Kebele" (which is the lowest hierarchy of governmental administration unit in Ethiopia), exhaustive fieldworks were carried out to approximate the location of accidents based on kilometer post along the study area. Then, the collected accidents have been applied for each segments of a road.

Traffic data has been used to undertake the analysis of road safety problems for the road under consideration. Traffic volumes in terms of AADT have been used as one of the inputs to estimate the theoretical accident frequency. Beside traffic volume, other pertinent data such as speed characteristics, non-motorized traffic and pedestrian characteristics and others were collected through reconnaissance survey and some interview with traffic police. These additional data were utilized in order to identify the causes of traffic accidents and to select the counter measures. Traffic data (AADT) that obtained from Ethiopian Road Authority (ERA) also include three years of the study period.

\subsection{Methods}

In this research, three quantitative measures were estimated in order to examine 
performances of the study sites. First, by using the empirical Bayes (EB) method the safety level of each road segments has been quantified, which represent long run average number of historical accident count. Second, the predicted number of accidents was quantified by using Safety Performance Function (SPF), which has been used as a performance threshold value. Finally, by using the two quantified crash frequencies in the above part the excess number of accidents from the expected average crash frequencies, which is called excess value or Potential for Safety Improvement (PSI) index, were estimated in order to measure the performance of each road segments and also for identification and ranking of dangerous road sections.

The EB method uses data from the crash history of a treated site, as well as information about the safety of reference sites with similar geometric characteristics. This is used to estimate how many crashes would have occurred at the treated site had it been no improvements made during the study period. The joint use of the information from treated and reference sites were based on a weighted average [22]. The estimate of the expected number of crashes at the treated site, $\mathrm{E}(k / K)$, given the site recorded $K$ crashes, can be estimated by using the following equations.

$$
\begin{gathered}
\mathrm{E}(k / K)=w * \mathrm{E}(k)+(1-w) * K \\
w=\frac{1}{1+\frac{\operatorname{Var}(k)}{\mathrm{E}(k)}}
\end{gathered}
$$

where, $K_{1}, K_{2}, K_{3}, \cdots, K_{n}$ are the number of crashes at references sites $1,2,3, \cdots, n$ respectively, whose characteristics were determined to be similar to those at the treated site; $\mathrm{E}(k)$ is the expected number of crashes at these reference sites; and $K$ is the actual crash count at a treated site, $\operatorname{Var}(k)$ is the variance of the expected number of crashes at the reference sites; and $w=$ weight factor, which can also be estimated based on over-dispersion parameter.

\subsection{Accident Prediction Model}

The general formula for the accident prediction model is composed of three components: 1) base model, 2) accident modification factors, and 3) calibration factor as given by [14]:

$$
\mathrm{E}(k)=\mathrm{SPF}_{\mathrm{br}} * \mathrm{Cr} *(\mathrm{AMF} 1 \mathrm{r} * \mathrm{AMF} 2 \mathrm{r} * \cdots * \mathrm{AMFnr})
$$

where, $\mathrm{E}(k)=$ predicted number of total roadway collisions per year after application of AMFs; $\mathrm{SPF}_{\mathrm{br}}=$ safety performance function which can be used to predicted number of total roadway collisions per year for nominal or base conditions of two lane rural highway; $\mathrm{Cr}=$ calibration factor; and AMF1r $\cdots$ AMFnr $=$ accident modification factors for roadway segments.

\subsubsection{Base Model}

Safety performance function is regression models for estimating the predicted 
average crash frequency of individual roadway segments. The base conditions for roadway segments on rural two-lane two-way roads that has been used to estimate SPF are shown in Table 1.

Based on the road parameters shown in Table 1, observed crash data for a set of similar sites and a wide range of AADT, from 0 up to 17,800 vehicles per day, a multivariate regression model which was established by Negative Binomial (NB) distribution, the base model of a two-lane two-way rural highway, is given by HSM [14] as:

$$
\mathrm{SPF}_{\mathrm{br}}=(\mathrm{AADT}) *(L) * 365 * 10^{-6} * \mathrm{EXP}^{-0.321}
$$

where, $\mathrm{AADT}=$ average annual daily traffic; and $L=$ length of segment (mile).

Evaluation of the fitting of SPF model to the specific sites should be assessed based on the following criterion. The model passes the goodness of fit criteria when the value of Pearson $X^{2}$ and Scaled Daviance $G^{2}$ statistics are greater than or equal to the value of $\chi^{2}$ statistics distribution with $(n-p)$ degree of freedom at $95 \%$ confidence level [26]. The coefficient of determination $\left(R^{2}\right)$ can also be used to determine the amount of variability in the response variable explained by the variation in the selected set of explanatory variables [27]. The Pearson $X^{2}$ and Scaled Daviance $G^{2}$ statistics for NB distribution were given by [26] [28].

$$
\begin{gathered}
X^{2}=\sum_{i=1}^{n} \frac{\left(y_{i}-\mu_{i}\right)^{2}}{\left(\mu_{i}+\alpha \mu_{i}^{2}\right)} \\
G^{2}=2 \sum_{i=1}^{n}\left\{\left(\ln \frac{y_{i}}{\mu_{i}}\right)^{y_{i}}-\left(y_{i}+\frac{1}{\alpha}\right) \ln \left(\frac{1+\alpha y_{i}}{1+\alpha \mu_{i}}\right)\right\}
\end{gathered}
$$

where, $y_{i}=$ observer number of accidents; $\mu_{i}=$ predicted number of accidents using SPF; $\alpha=$ dispersion parameter.

Table 1. Base conditions for two-lane two-way rural road [14].

\begin{tabular}{ccc}
\hline No. & Road parameters & Base conditions \\
\hline 1 & Lane width & $3.66 \mathrm{~m}$ \\
2 & Shoulder width & $1.83 \mathrm{~m}$ \\
3 & Shoulder type & Paved \\
4 & Roadside hazard rating (RHR) & 3 \\
5 & Driveway density (DD) & 5 per mile \\
6 & Horizontal curvature & None \\
7 & Vertical curvature & None \\
8 & Centerline rumble strips & None \\
9 & Passing lanes & None \\
10 & Two-way left-turn lanes & None \\
11 & Lighting & None \\
12 & Automated speed enforcement & None \\
13 & Grade Level & $0 \%$
\end{tabular}


The dispersion parameter can be estimated from observed data using the method of moments as a function of the variance and the mean was determined by [28] as:

$$
\operatorname{VAR}\left(Y_{i}\right)=\bar{y}_{i}+\alpha \bar{y}_{i}^{2}
$$

where, $\operatorname{VAR}\left(Y_{i}\right)=$ variance of accident count, and $\bar{y}=$ mean of accident count.

\subsubsection{Accident Modification Factors}

The factors that are accounted for by the AMFs are mainly the differences in geometric and design features from base condition, HSM provides twelve AMFs in the form of equations, tables and/or graphs. Of these factors, only eight of them were considered. The remaining factors were excluded because they were similar with the base condition. The AMFs for geometric design and traffic control features of rural two-lane two-way roadway segments are presented in Table 2.

\subsubsection{Calibration Factor}

The other factor that affect collision occurrence, in addition to geometric and design features, is called calibration factor. Calibration provides a method to account for differences between jurisdictions in factors such as climate, driver populations, animal populations, accident reporting thresholds, and accident reporting system procedures. For that reason, as given by HSM [14], mathematically calibration factor $(\mathrm{Cr})$ can be estimated as:

Table 2. AMFs equations for geometric design and traffic control features of two-lane road [14].

\begin{tabular}{|c|c|c|c|}
\hline No. & Road parameters & Accident Modification Factors (AMF) & Where \\
\hline 1 & Lane Width & $\mathrm{AMFlr}=(\mathrm{AMFra}-1) * \operatorname{Pra}+1$ & $\begin{array}{l}\text { AMFra = AMF of related accidents, } \\
\text { Pra = proportion of related accidents, }\end{array}$ \\
\hline 2 & Shoulder Width & AMF2r $=($ AMFwra $*$ AMFtra -1$) * \operatorname{Pra}+1$ & $\begin{array}{l}\text { w \& t indicate width \& types } \\
\text { of shoulder respectively }\end{array}$ \\
\hline 3 & Horizontal Curves (HC) & $\mathrm{AMF} 3=\frac{1.55 * L c+\frac{80.2}{R}-0.012 * S^{*}}{1.55 * L c}$ & $\begin{array}{c}L c=\mathrm{HC} \text { length }(\mathrm{mi}) \\
S=\text { spiral curve and } \\
R=\mathrm{HC} \text { radius }(\mathrm{ft})\end{array}$ \\
\hline 4 & Super elevation & $\begin{array}{c}\text { AMF4 }=1.00 \text { for } \mathrm{SV}<0.01 ; \\
\mathrm{AMF} 4=1.00+6 *(\mathrm{SV}-0.01) \text { for } 0.01 \leq \mathrm{SV}<0.02 \\
\mathrm{AMF} 4=1.06+3 *(\mathrm{SV}-0.02) \text { for } \mathrm{SV} \geq 0.02\end{array}$ & $\mathrm{SV}=$ super elevation variation $(\mathrm{m} / \mathrm{m})$ \\
\hline 5 & Grades & $\begin{array}{c}G \leq 3 \%, \text { AMF5 }=1.00 ; 3 \%<G \leq 6 \%, \text { AMF5 }=1.10 \\
\text { and } G>6 \% \text {, AMF5 }=1.16\end{array}$ & $G=$ grade of the road \\
\hline 6 & Driveway Density & $\mathrm{AMF} 6=\frac{0.322+\mathrm{DD} *(0.05-0.005 * \ln (\mathrm{AADT}))}{0.322+5 *(0.05-0.005 * \ln (\mathrm{AADT}))}$ & $\mathrm{DD}=$ driveway density \\
\hline 7 & Roadside Design & AMF7 $=\frac{\exp (-0.6869+0.0668 * \text { RHR })}{\exp (-0.4865)}$ & RHR $=$ road hazard rating \\
\hline 8 & Passing Lanes & AMF8 for short four-lane sections $=0.65$ & AMF8 applied only for short four-lane section \\
\hline
\end{tabular}

$\mathrm{S}^{*}=1$ if spiral transition curve is present; 0 if spiral transition curve is not present; 0.5 if a spiral transition curve is present at one but not both ends of the horizontal curve. 


$$
\mathrm{Cr}=\frac{\sum_{\text {all site }}(\text { Observed Crashes })}{\sum_{\text {all site }}(\text { Predicted Crashes })}
$$

\subsection{Expected Average Crash Frequency with Empirical Bayes (EB) Adjustment}

The Empirical Bayes (EB) method applied in the estimation of expected average crash frequency used yearly correction factors for consistency with network screening applications in the Safety Analyst software tools. The following steps of estimation of expected average crash frequency with Empirical Bayes adjustments were followed [14].

$S T E P 1$-The predicted average crash frequency is estimated from $\operatorname{SPF}, \mathrm{E}(k)_{n}$, using base model, AMFs and calibration factor for each study year $n$, where, $n=$ $1,2,3$.

STEP 2-The annual correction factor is given as predicted average crash frequency for year $n$ divided by the predicted average crash frequency for year 1 . This factor is intended to capture the effect that annual variations in traffic, weather, and vehicle mix have on crash occurrences.

$$
C_{n}=\frac{\mathrm{E}(k)_{n}}{\mathrm{E}(k)_{1}}
$$

where, $C_{n}=$ Annual correction factor for total crashes; $\mathrm{E}(k)_{n}=$ Predicted number of crashes for year $n ; \mathrm{E}(k)_{1}=$ Predicted number of crashes for year 1 .

STET 3-Weighted adjustment

This step of the EB method is to determine the relative weight, $w$, which can be estimated by using Equation (2).

STEP 4-First year EB-adjusted expected average crash frequency expression was established by applying the correction factor, $C_{n}$, on Equation (1).

$$
\mathrm{E}(k / K)_{1}=w * \mathrm{E}(k)_{1}+(1-w) \frac{\sum_{\text {all year }}\left(K_{n}\right)}{\sum_{\text {all year }}\left(C_{n}\right)}
$$

where, $\mathrm{E}(k / K)_{1}=\mathrm{EB}$-adjusted expected average crash frequency for year $1 ; K_{n}=$ Observed crash frequency along each segment for year $n(n=1,2$ or 3$)$; and $n=$ study years(1, 2 or 3 in the respective order from 2012/13 up to 2014/15).

STEP 5-The EB-adjusted expected number of total crashes for the final year can be estimated using the following equation (the final year is year 3 , which is 2014/15).

$$
\mathrm{E}(k / K)_{n}=\mathrm{E}(k / K)_{1} \times C_{n}
$$

\subsection{Identification and Ranking of Dangerous Sites}

\subsubsection{Identifying Dangerous Sites}

Based on the selected performance measure, which is excess expected average crash frequency and commonly called potential for safety improvement (PSI) could be calculated by Equation (12). Therefore, dangerous sites can be identified when the difference between EB estimate and the normal number of accident 
expected from such types of sites become positive.

$$
\text { Excess Value }=\mathrm{E}(k / K)_{n}-\mathrm{E}(k)_{n}
$$

Excess value $(\mathrm{PSI})=$ Excess number of accidents from expected crashes frequency for year, $n$

\subsubsection{Ranking Locations}

After dangerous locations were identified, next step is to rank the road segments for priority treatment. Having calculated the excess expected number of accidents for each homogeneous road section, they have been listed in a decreasing order of the excess expected number of accidents value. Hence, the higher the position of the road section in the list is the more hazardous compared to the other sections in the list.

\section{Results and Discussions}

The concept of hazardous location (HL) identification assumes that there are road with engineering deficiencies, which do not function properly from a safety viewpoint. The process of HL identification is intended for an initial screening of road sites, in order to focus on sites more promising in terms of potential benefits of intervention. This process can be described as an examination of accident frequencies on road sites of the study area, in order to point out the sites with irregularly high accident numbers.

\subsection{Base Model Calibration (Modification)}

To estimate the calibration factor the predicted number of accidents for each segments were calculated by using base modal and accident modification factors. Thus, the total number of three years predicted accidents before calibration were estimated to be 185.4 while the corresponding actually occurred number of accidents was 280 . Then, the calibration factor $(\mathrm{Cr})$ was computed to be 1.51 . Therefore, the calibration factor equals to 1.51 should be used in order to adjust SPF to reflect the difference accident frequencies between this study area and the base model was established. After application of calibration factor, the base model given in Equation (4) has been modified in to the local condition and given by:

$$
\mathrm{SPF}_{\mathrm{br}}=1.51 *(\mathrm{AADT}) *(L) * 365 * 10^{-6} * \mathrm{EXP}^{-0.321}
$$

\subsection{Accidents Estimation}

Based on the four steps in EB safety estimation procedure the predicted number of accident, annual correction factors, relative weight and EB-adjusted expected average crash frequency values were determined. Predicted number of accidents for each road segments was estimated using the calibrated or modified base model to local condition as shown Equation (13) and AMFs. Using three years predicted accident frequencies the annual correction factor for each study year of each road segment was estimated using Equation (9) as presented in Table 3. 
Table 3. Annual correction factors, weight factor, observed, predicted and expected yearly crash frequencies.

\begin{tabular}{|c|c|c|c|c|c|c|c|c|c|c|c|}
\hline \multirow[t]{2}{*}{$\begin{array}{l}\text { Segment } \\
\text { Code }\end{array}$} & \multicolumn{3}{|c|}{$\begin{array}{l}\text { Predicted Average } \\
\text { Crash Frequency }\end{array}$} & \multicolumn{3}{|c|}{$\begin{array}{c}\text { Annual } \\
\text { Correction } \\
\text { Factors } \\
(\mathrm{ACF})\end{array}$} & $\begin{array}{c}\text { Total } \\
\text { CF }\end{array}$ & \multirow[t]{2}{*}{$\begin{array}{l}\text { Weight } \\
\text { Factor }\end{array}$} & \multirow{2}{*}{$\begin{array}{c}\text { Average } \\
\text { Observed } \\
\text { Accident } \\
\text { Frequency } \\
\text { per year } \\
K\end{array}$} & \multicolumn{2}{|c|}{$\begin{array}{c}\text { EB Adjusted } \\
\text { Expected Average } \\
\text { Crash Frequency }\end{array}$} \\
\hline & $2012 / 13$ & $2013 / 14$ & $2014 / 15$ & $C_{1}$ & $C_{2}$ & $C_{3}$ & $C_{\text {total }}$ & & & $\mathrm{E}\{k / K\}_{1}$ & $\mathrm{E}\{k / K\}_{3}$ \\
\hline 120 & 2.06 & 2.20 & 2.36 & 1.00 & 1.07 & 1.14 & 3.21 & 0.33 & 1.0 & 1.31 & 1.49 \\
\hline 121 & 1.99 & 2.13 & 2.28 & 1.00 & 1.07 & 1.14 & 3.21 & 0.34 & 0.3 & 0.88 & 1.01 \\
\hline 122 & 1.80 & 1.92 & 2.06 & 1.00 & 1.07 & 1.14 & 3.21 & 0.36 & 2.3 & 2.04 & 2.33 \\
\hline 123 & 1.80 & 1.92 & 2.06 & 1.00 & 1.07 & 1.14 & 3.21 & 0.36 & 2.0 & 1.84 & 2.11 \\
\hline 124 & 1.80 & 1.92 & 2.06 & 1.00 & 1.07 & 1.14 & 3.21 & 0.36 & 0.7 & 1.05 & 1.20 \\
\hline 125 & 1.80 & 1.92 & 2.06 & 1.00 & 1.07 & 1.14 & 3.21 & 0.36 & 0.0 & 0.65 & 0.74 \\
\hline 126 & 1.92 & 2.06 & 2.20 & 1.00 & 1.07 & 1.14 & 3.21 & 0.35 & 0.3 & 0.87 & 0.99 \\
\hline 127 & 1.95 & 2.09 & 2.24 & 1.00 & 1.07 & 1.14 & 3.21 & 0.34 & 1.0 & 1.28 & 1.47 \\
\hline 128 & 1.95 & 2.09 & 2.24 & 1.00 & 1.07 & 1.14 & 3.21 & 0.34 & 2.3 & 2.10 & 2.40 \\
\hline 129 & 1.80 & 1.92 & 2.06 & 1.00 & 1.07 & 1.14 & 3.21 & 0.36 & 1.0 & 1.24 & 1.42 \\
\hline 130 & 1.82 & 1.95 & 2.09 & 1.00 & 1.07 & 1.14 & 3.21 & 0.36 & 0.7 & 1.05 & 1.20 \\
\hline 131 & 2.15 & 2.30 & 2.46 & 1.00 & 1.07 & 1.14 & 3.21 & 0.32 & 2.3 & 2.17 & 2.48 \\
\hline 132 & 2.11 & 2.26 & 2.42 & 1.00 & 1.07 & 1.14 & 3.21 & 0.32 & 2.0 & 1.95 & 2.23 \\
\hline 133 & 2.16 & 2.31 & 2.47 & 1.00 & 1.07 & 1.14 & 3.21 & 0.32 & 2.7 & 2.38 & 2.73 \\
\hline 134 & 2.18 & 2.33 & 2.50 & 1.00 & 1.07 & 1.14 & 3.21 & 0.32 & 0.7 & 1.12 & 1.28 \\
\hline 135 & 2.59 & 2.77 & 2.97 & 1.00 & 1.07 & 1.14 & 3.21 & 0.28 & 2.7 & 2.52 & 2.88 \\
\hline 136 & 1.92 & 2.06 & 2.20 & 1.00 & 1.07 & 1.14 & 3.21 & 0.35 & 3.0 & 2.50 & 2.86 \\
\hline 137 & 2.23 & 2.39 & 2.56 & 1.00 & 1.07 & 1.14 & 3.21 & 0.31 & 2.3 & 2.19 & 2.51 \\
\hline 138 & 2.60 & 2.79 & 2.98 & 1.00 & 1.07 & 1.14 & 3.21 & 0.28 & 3.7 & 3.19 & 3.65 \\
\hline 139 & 2.56 & 2.73 & 2.93 & 1.00 & 1.07 & 1.14 & 3.21 & 0.28 & 1.7 & 1.84 & 2.11 \\
\hline 140 & 2.13 & 2.28 & 2.44 & 1.00 & 1.07 & 1.14 & 3.21 & 0.32 & 1.0 & 1.32 & 1.51 \\
\hline 141 & 1.68 & 1.79 & 1.92 & 1.00 & 1.07 & 1.14 & 3.21 & 0.38 & 2.0 & 1.79 & 2.05 \\
\hline 142 & 2.15 & 2.30 & 2.46 & 1.00 & 1.07 & 1.14 & 3.21 & 0.32 & 3.3 & 2.80 & 3.21 \\
\hline 146 & 2.49 & 2.67 & 2.85 & 1.00 & 1.07 & 1.14 & 3.21 & 0.29 & 1.3 & 1.61 & 1.84 \\
\hline 147 & 2.11 & 2.26 & 2.42 & 1.00 & 1.07 & 1.14 & 3.21 & 0.32 & 0.7 & 1.11 & 1.27 \\
\hline 148 & 2.30 & 2.46 & 2.64 & 1.00 & 1.07 & 1.14 & 3.21 & 0.31 & 3.7 & 3.08 & 3.52 \\
\hline 149 & 2.33 & 2.50 & 2.67 & 1.00 & 1.07 & 1.14 & 3.21 & 0.30 & 4.7 & 3.74 & 4.28 \\
\hline 150 & 1.43 & 1.54 & 1.64 & 1.00 & 1.07 & 1.14 & 3.21 & 0.41 & 1.7 & 1.51 & 1.72 \\
\hline 151 & 1.90 & 2.03 & 2.17 & 1.00 & 1.07 & 1.14 & 3.21 & 0.35 & 5.0 & 3.70 & 4.24 \\
\hline 152 & 3.95 & 4.22 & 4.52 & 1.00 & 1.07 & 1.14 & 3.21 & 0.20 & 6.7 & 5.76 & 6.59 \\
\hline 153 & 2.88 & 3.08 & 3.30 & 1.00 & 1.07 & 1.14 & 3.21 & 0.26 & 2.3 & 2.36 & 2.70 \\
\hline 154 & 3.06 & 3.27 & 3.50 & 1.00 & 1.07 & 1.14 & 3.21 & 0.25 & 4.7 & 4.03 & 4.61 \\
\hline
\end{tabular}




\begin{tabular}{|c|c|c|c|c|c|c|c|c|c|c|c|}
\hline Contin & & & & & & & & & & & \\
\hline 155 & 1.68 & 1.79 & 1.92 & 1.00 & 1.07 & 1.14 & 3.21 & 0.38 & 1.3 & 1.41 & 1.61 \\
\hline 161 & 1.58 & 1.66 & 1.74 & 1.00 & 1.05 & 1.10 & 3.15 & 0.40 & 2.0 & 1.78 & 1.96 \\
\hline 162 & 1.58 & 1.66 & 1.74 & 1.00 & 1.05 & 1.10 & 3.15 & 0.40 & 1.7 & 1.58 & 1.75 \\
\hline 163 & 1.64 & 1.72 & 1.81 & 1.00 & 1.05 & 1.10 & 3.15 & 0.39 & 2.7 & 2.19 & 2.42 \\
\hline 164 & 1.81 & 1.90 & 1.99 & 1.00 & 1.05 & 1.10 & 3.15 & 0.36 & 3.7 & 2.88 & 3.17 \\
\hline 165 & 2.05 & 2.16 & 2.26 & 1.00 & 1.05 & 1.10 & 3.15 & 0.34 & 5.3 & 4.06 & 4.48 \\
\hline 166 & 1.56 & 1.64 & 1.72 & 1.00 & 1.05 & 1.10 & 3.15 & 0.40 & 2.3 & 1.96 & 2.16 \\
\hline 167 & 1.53 & 1.61 & 1.69 & 1.00 & 1.05 & 1.10 & 3.15 & 0.40 & 1.3 & 1.38 & 1.52 \\
\hline 168 & 1.45 & 1.53 & 1.60 & 1.00 & 1.05 & 1.10 & 3.15 & 0.42 & 1.0 & 1.16 & 1.28 \\
\hline 169 & 1.45 & 1.53 & 1.60 & 1.00 & 1.05 & 1.10 & 3.15 & 0.42 & 0.7 & 0.98 & 1.08 \\
\hline 170 & 1.45 & 1.53 & 1.60 & 1.00 & 1.05 & 1.10 & 3.15 & 0.42 & 1.7 & 1.53 & 1.69 \\
\hline
\end{tabular}

Note: Year 1, 2 and 3 represent $1^{\text {st }}, 2^{\text {nd }}$ and $3^{\text {rd }}$ years of study period $(2012 / 13-2014 / 15)$ respectively.

The relative weights, as depicted in Table 3, used in EB method for each segment was estimated based on over-dispersion parameter (ODP) and predicted number of accidents, where ODP was estimated by using Equation (7). The next step of the method, integrates the observed crash frequency with the predicted average crash frequency by weight factor in order to estimate the EB-adjusted expected average crash frequency, which can represent the accident potential of a site or the long-term average actually occurred number of accidents. Accordingly, the result of expected long term first year and final year EB-adjusted average crash frequency on the roadway segments estimated and presented in Table 3.

The larger the weighting factor indicates that the greater the reliance on the predicted accidents than the observed to estimate the long-term predicted average crash frequency per year at the site [13] [14]. The estimated weight factors, $\mathrm{w}$, varies from 0.20 up to 0.42 as shown in Table 3. On the other hand, the complementary weight $(1-w)$ varies from 0.80 up to 0.58 , which is given for observed accident frequency. The mean and variance of accident count data were 6.51 and 19.50 respectively, which indicated that the data set was over-dispersed because the variance exceeds the mean. This indicates that the traffic accident data gathered from the study site were significantly dispersed, therefore, the reliability of the predicted accidents frequency are less reliable than the observed accident frequency. Accordingly, it is reasonable to obtain less weight to predicted accident frequency and more weight for observed number of accidents.

\subsection{Model Validation}

Two statistical measures were used in assessing the validity of the model developed. These were the Pearson Chi-square statistic and Deviance statistic. The Pearson Chi-square and Deviance statistics were estimated to be 30.7 and 37.4 respectively. These values are within the permissible range, which are less or 
equals to $\chi_{0.05,35}^{2}=46$ indicating that the Negative Binomial distribution assumption is acceptable. Therefore, the goodness-of-fit statistics for the model shows that the model output fits reasonably well with the observed data.

\subsection{Dangerous Road Sites}

According to the selected performance measure and detail procedure described in the methodology part, dangerous road segments and the corresponding performance measure and threshold value were estimated. As the result shown almost $50 \%$ of the road segments under study were found to be dangerous (Figure 3).

The identification of dangerous road segments were based on a criterion that its accident potential exceeds the value that is normal (i.e. performance threshold value) for similar such types of sites in reference population. Therefore, when the excess expected crash frequency value became greater than zero, a site experiences more crashes than expected otherwise a site experiences less crashes than expected. For example, segment 122 has experienced 0.23 accidents per year more than the expected threshold value, which can be expected from such types of roads. Hence, there will be a potential to reduce as equal number of accident per year with minor improvement along this segment. Accordingly, based on excess or PSI values out of 43 road segments 22 of them were identified as dangerous road segments as indicated in Figure 3. In total around 16 number of excess accidents can be expected from the identified 22 dangerous sites per year.

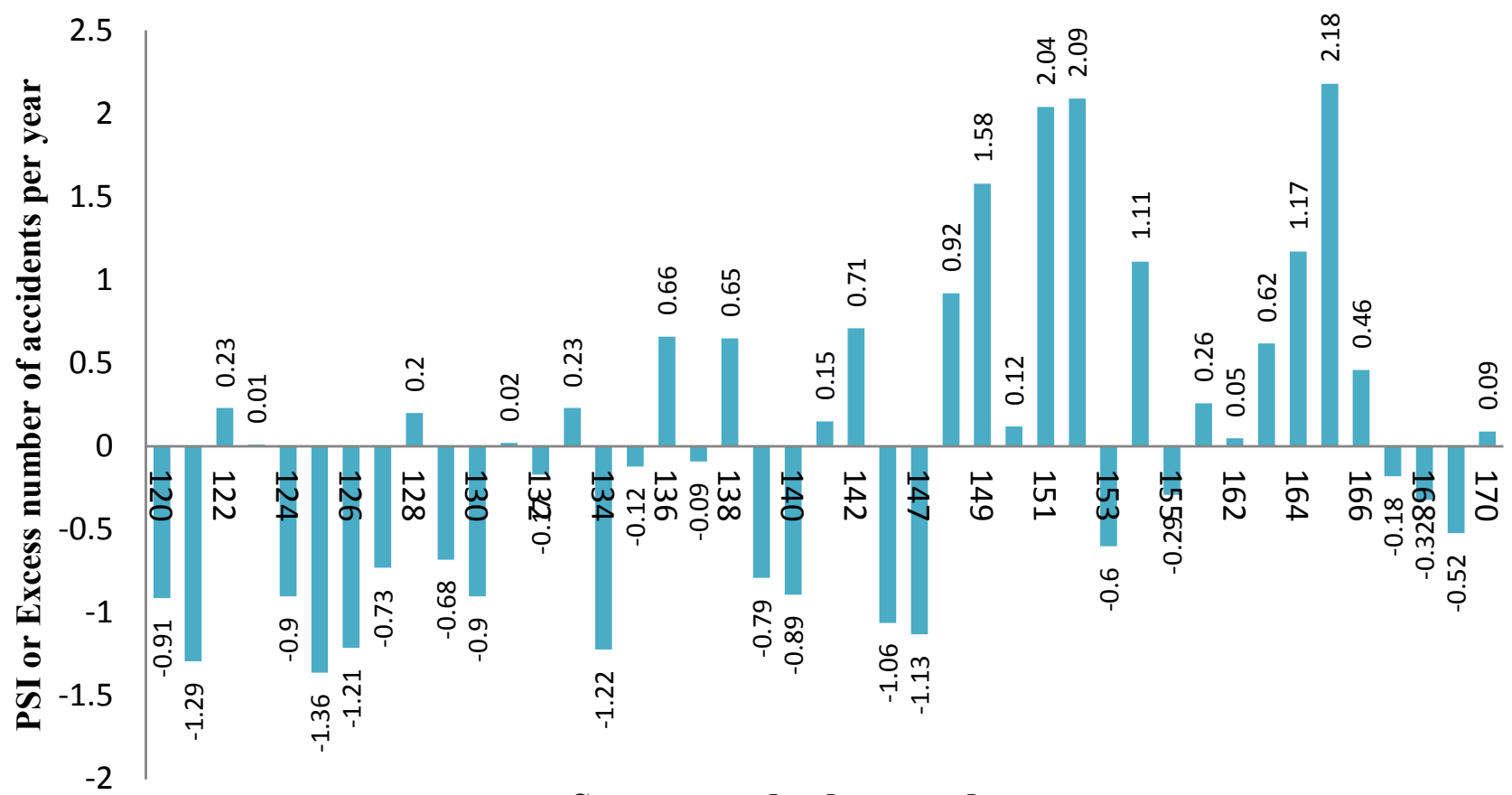

\section{Segment code along study area}

- Excess number of expected accidents per year

Figure 3. Distribution of PSI or excess number of accidents from expected values along study area. 


\subsection{Ranking Road Sites Based on PSI Values}

The identified dangerous road segments in the above section were ranked according to their PSI values. The result of the analysis presented in Figure 4 revealed that the PSI values of dangerous sites were ordered from left to right in a decreasing order. The one that has ranked at the left has high potential to reduce a number of accidents compared to the other road sites in the ranked list after treatments will be applied. This implied that the higher the value of PSI in the ranked list of dangerous segments the more dangerous compared to the other sites in the list.

As shown in Figure 4, segment 165, which was ranked in the first position, in the rural two-lane two-way trunk road reference population, has a potential for reducing the average crash frequency by 2.21 crashes per year (i.e. around $14 \%$ of total excess number of accidents in the study area). Therefore, Segment 165 would be ranked at the first position as compared to other segments according to the highest excess expected crash frequency. Similarly, segment 152, which took the second place, has a potential for reducing the average crash frequency by 2.07 crashes per year (which contributed around 13\% of total excess number of accidents in the study area). On the other hand, if segment 162, which was ranked in the last position (i.e. ranked in $22^{\text {nd }}$ position), is treated it has a potential for reducing the average crash frequency by 0.003 crashes per year. This is the reason why prioritization of individual sites was made within a reference population.

On the other hand, due to the random nature of accident any one should not expect that a treatment could bring a road site into zero accident level. For that reason, the occurrence of accidents can be influenced by pure random variation and also by systematic random variation. This study focuses only on the systematic variation part, which is attributable by various road and traffic factors that

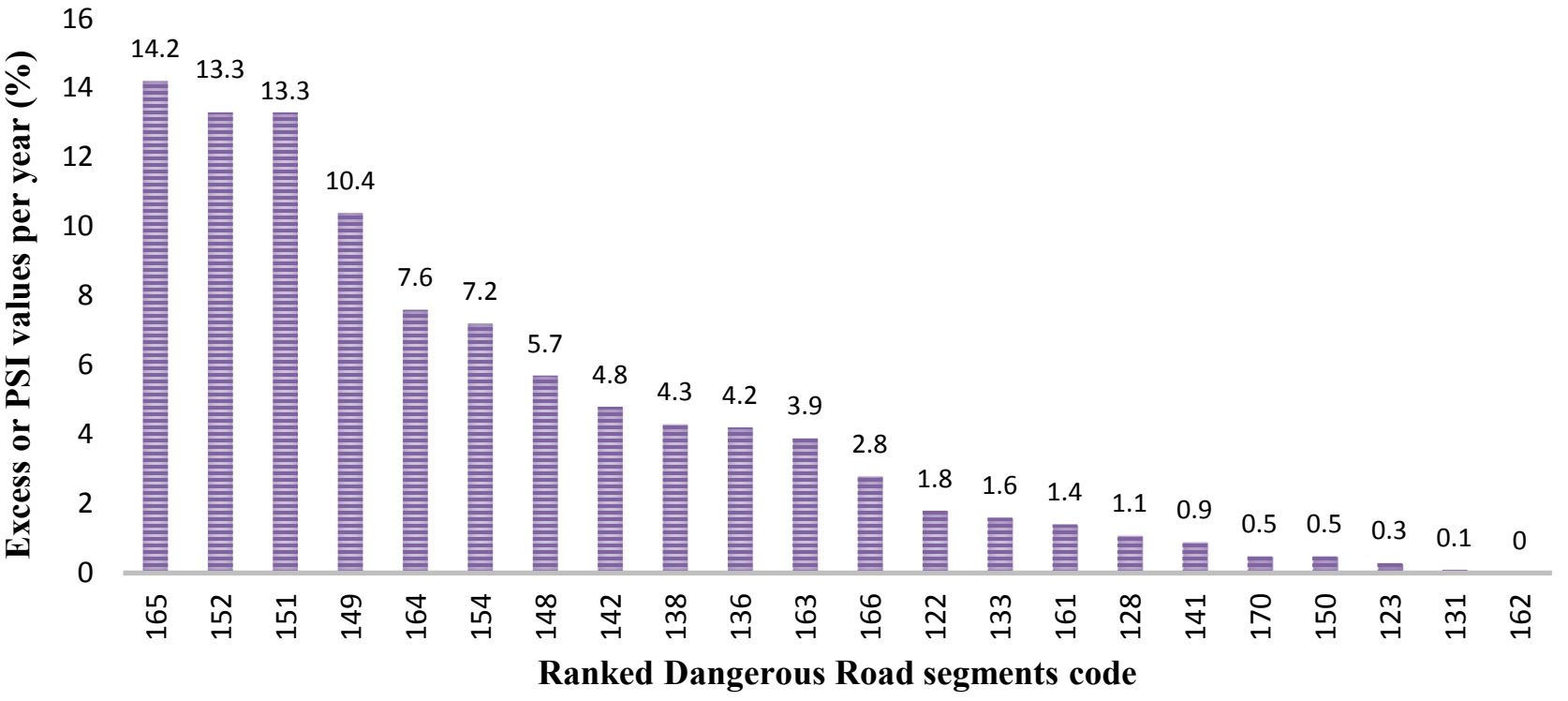

Figure 4. Ranking dangerous road segments. 
can be controlled by applying treatments because the pure random variation part cannot be controlled, as long as there are exposure (vehicle-km driven) accidents shall encountered. As indicated in Figure 4, this study identified that in total around 16 excess accidents can be expected from the identified 22 dangerous sites per year. The next step is to mitigate these systematically occurred excess numbers of accidents by applying remedial treatment in order to bring the number of accidents back to the normal condition, which is representative for all similar road segments in the reference population.

The frequencies of observed, predicted and expected accidents along the ranked dangerous road segments were analyzed and summarized as in Figure 5. The order of the segments in the figure was irrespective of any of the stated accidents but it was based on the decreasing order of PSI values similar to Figure 4. If we use either of the specified accident frequencies to evaluate the performance of the road sites, we may wrongly give high priority for safe or less dangerous segments than unsafe or more dangerous segments. For instance, as indicated in Figure 5, the distribution of observed, predicted and expected number of accidents along segment 165, which was ranked in the first position, were less than the respective values along segment 152, ranked in the second position. Similarly, when we see the pairs of adjacent segments such as $(164,154),(142,138)$, $(122,133),(161,128),(150,123)$ and $(123,131)$ the former segments have experienced larger PSI values, but they experienced less number of all the three accidents (observed, predicted and expected) than the latter segments respectively. Accordingly, in order to improve the performance of an existing roads with only minor improvements this study found that the larger the number of accidents along a given segment does not necessarily mean that the more dangerous when it is compared to the other road segments in the reference population. This indicates that in order to normalize total number of accidents and fatalities along the existing roads in the country level it is very important to identify the promising road sites using the best and advanced techniques. Then, prioritization of the identified promising sites is a critical issue in order to allocate limited budget for the most promising section of roads. For that matter, the findings of this

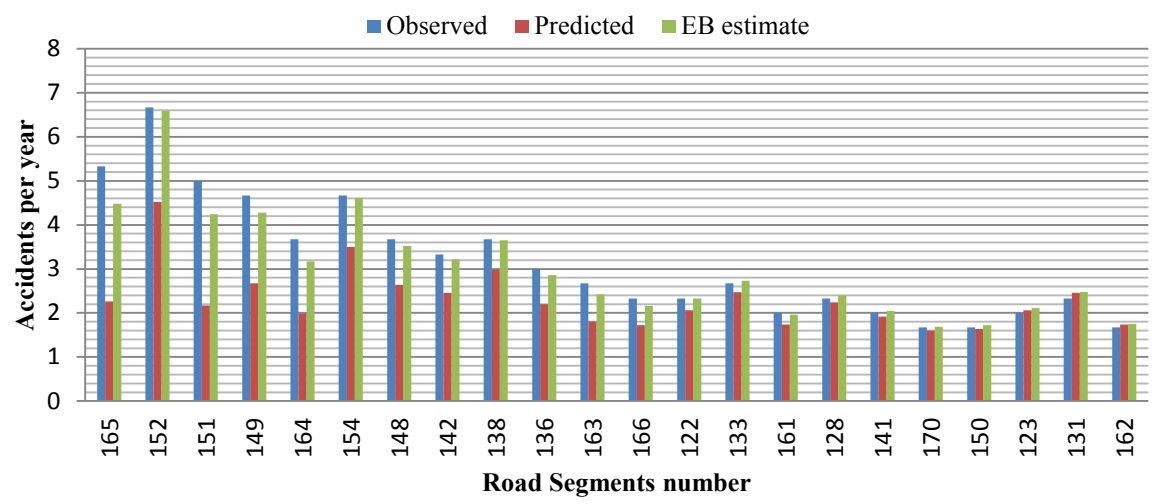

Figure 5. Distribution of observed, predicted and expected number of accidents along ranked dangerous segments. 
study will be useful for further implementation of the road safety measures along existing dangerous road segments and also a baseline for similar studies in the country.

\subsection{Prioritization of Dangerous Road Segments Based on Average PSI Values}

In this research, the ranked road segments have been further grouped for remedial treatment in order to allocate the limited budget for the most dangerous road segments. To facilitate this grouping process, two average PSI values have been estimated and these average PSI values split the ranked 22 road sites up in to three parts as shown below:

First, the average PSI $\left(\sum_{r=1}^{n}\right.$ PSIi $\left./ n\right)$ values of 22 road sites was estimated and those road sites which exhibit greater than or equals to this average PSI value (which is equals to 0.71 ) were categorized in to the first group. Accordingly, eight road segments were included in this group.

Second, excluding 8 from the ranked 22 segments the average PSI value of the remaining 14 sites (which is equals to 0.26 ) have been used for further grouping of those 14 sites. Based on this criterion, those segments having PSI values between 0.71 and 0.26 were categorized in to the second group. The remaining road sites were grouped in the third category as clearly indicated in Table 4.

Group I-hazardous sites with a relatively high excess expected number of accidents than the average of all dangerous road segments (i.e., 0.71 excess number of accidents) were singled out as the most dangerous road segments. This implies that if only the top 8 hazardous sites (which covers $36.4 \%$ of the total length of hazardous road section) will be treated, around $76 \%$ of excess amount of expected accidents frequencies can be reduced. Hence, this group was placed at the top of group rank and must be analyzed and subjected to special purpose inspections in order to identify the influencing factors and to select appropriate types of measures. Therefore, such sites would be considered having certainly a higher potential of safety improvement after applying the required measures.

Group II-hazardous sites with a relatively moderate excess PSI values or those sites having potential to reduce from 0.26 up to 0.71 crash per year were grouped into second category. Accordingly, out of 22 dangerous segments 6 of them were included in this group. Even though these road sites cover $27.3 \%$ of total length of hazardous road section, they have a potential to reduce only 3

Table 4. Prioritization of group of dangerous segments.

\begin{tabular}{cccccc}
\hline \multirow{2}{*}{ Category } & \multicolumn{2}{c}{ Excess or PSI Values per year } & \multicolumn{2}{c}{ Proportion of Segments } & $\begin{array}{c}\text { Group Rank for } \\
\text { Treatment }\end{array}$ \\
\cline { 2 - 5 } & In number & In per cent & In number & In per cent & 36.36 \\
\hline Group I & 11.90 & 76 & 8 & 27.27 & 2 \\
Group II & 3.00 & 19 & 6 & 36.36 & 3 \\
Group III & 0.76 & 5 & 22 & 100 & \\
Total & 15.57 & 100 & &
\end{tabular}


numbers of excess accidents per year, which accounted for around 19\% of total number of excess accidents. Hence, they were ranked in the second position of group rank and it would not necessarily be recommended to consider these sites as having a high potential of safety improvement.

Group III-hazardous sites with a relatively least excess value or those having potential to reduce less than 0.26 crash per year were grouped into third category. Accordingly, out of 22 dangerous segments 8 segments were included in this group. If these road sites, which cover as equal length as Group I hazardous road section, will be treated only 0.76 numbers of excess accidents can be saved per year, which accounted for around 5\% of total number of excess accidents. Hence, they were ranked in the third position of group rank and it would be recommended not to consider these sites as having a high potential of safety improvement.

Therefore, those sites higher on the list, when they ordered in a decreasing order from top to bottom, are considered most likely to benefit from countermeasures intended to reduce crash frequency. Hence, the identified most dangerous sites that were ranked in the first group should be analyzed in more detail in order to identify the possible risk-indicating road and traffic factors and then to identify what kinds of improvements are likely to be most effective.

\subsection{Countermeasures}

The countermeasure selection has been made by evaluating the potential for safety improvement if appropriate countermeasures are applied. Countermeasures have been targeted a particular crash type or contributing factors. Table 5 shows the selected countermeasures and the identified risk indicating factors for the most dangerous 8 road sites. The contributing road and traffic factors were identified through exhaustive fieldwork, in depth analysis of historical accidents and reviewing as built drawing of the identified most dangerous road segments.

Accordingly, for example, the result of the detail investigation along segment 165 (which is ranked in the first place) shows that several risk-indicating road and traffic factors have been identified and the significant factors along this segment noted as:

High number of non-motorized traffic and pedestrians share traffic lane due to village settlement around this segment;

Sharp and unexpected horizontal curve after long tangent;

Inappropriate coordination of horizontal and vertical curves in both direction have been observed along this segment (In particular, the coincidence of a right horizontal curve and a crest vertical curve, which may lead to significant limitation of the available sight distance and prevent the prompt perception of the curve. Similarly, the coincidence of a left horizontal curve and a sag vertical curve may create a false impression of the degree of curvature);

Narrow shoulder width coupled with high fill and steep side slop along outer edge of horizontal curve; and, 
Table 5. Summary of excess amount of accidents, the major contributing factors of accidents and proposed countermeasures along the worst eight segments.

\begin{tabular}{|c|c|c|c|c|c|}
\hline \multirow{2}{*}{$\begin{array}{l}\text { Segment } \\
\text { Code }\end{array}$} & \multicolumn{2}{|c|}{ PSI per year } & \multirow{2}{*}{ Rank } & \multirow{2}{*}{ Crash contributing road and traffic factors } & \multirow{2}{*}{ Proposed countermeasures } \\
\hline & No. & $(\%)$ & & & \\
\hline 165 & 2.2 & 14.2 & 1 & $\begin{array}{l}\text { Due to village settlement around the road high } \\
\text { number of non-motorized traffic (NMT) \& } \\
\text { pedestrians directly access the road, lack of separate } \\
\text { lane for NMT, sharp and unexpected curve after long } \\
\text { tangent especially for unfamiliar drivers, inappropriate } \\
\text { coordination of horizontal and vertical curves }\end{array}$ & $\begin{array}{l}\text { Warning sign with speed limit, text on road surface } \\
\text { \& pedestrian crossing, construction of painted } \\
\text { guardrails outside the curves, installation of } \\
\text { rumble strips to reduce speed, widening shoulder } \\
\text { width, flattening side slope, segregating fast moving } \\
\text { and slow moving traffics by constructing separate } \\
\text { lanes for NMT }\end{array}$ \\
\hline 152 & 2.1 & 13.3 & 2 & $\begin{array}{l}\text { High number of pedestrians \& NMT directly access } \\
\text { the road, lack of separate lane for NMT, } 4 \text { HC per } \\
\text { segment, narrow culver, sharp HC, sight distance } \\
\text { problem due to roadside obstacles and inappropriate } \\
\text { coordination of horizontal and vertical curves. }\end{array}$ & $\begin{array}{l}\text { Warning sign with speed limit, marking of road } \\
\text { edge and centerline, text on road surface \& } \\
\text { pedestrian crossing, removing roadside obstacles, } \\
\text { avoid frontage access, segregating fast moving \& } \\
\text { slow moving traffics by constructing } \\
\text { separate lanes for NMT. }\end{array}$ \\
\hline 151 & 2.1 & 13.3 & 3 & $\begin{array}{l}\text { High number of pedestrian \& NMT directly access the } \\
\text { road, narrow lane and shoulder width, rolling terrain, } \\
\text { high number of VC per segment }\end{array}$ & $\begin{array}{l}\text { Warning sign with speed limit, marking of road } \\
\text { edge and centerline, text on road surface \& pede- } \\
\text { strian crossing, increasing shoulder width }\end{array}$ \\
\hline 149 & 1.6 & 10.4 & 4 & $\begin{array}{l}\text { Narrow bridge and approach road, rolling terrain, } \\
\text { and minor junction inside the horizontal curve. }\end{array}$ & $\begin{array}{l}\text { Warning sign with speed limit, road edge \& } \\
\text { centerline marking, painting beams and } \\
\text { column of bridge rail. }\end{array}$ \\
\hline 164 & 1.2 & 7.6 & 5 & $\begin{array}{l}\text { Long tangent with rolling terrain, high number of } \\
\text { non-motorized traffic due to village settlement }\end{array}$ & $\begin{array}{l}\text { Warning sign with speed limit, installation } \\
\text { of rumble strips, pavement markings }\end{array}$ \\
\hline 154 & 1.1 & 7.2 & 6 & $\begin{array}{l}\text { Narrow culver, three HC within a segment, sight } \\
\text { distance problem due to road side obstacles and } \\
\text { inappropriate combination of horizontal \& } \\
\text { vertical curves }\end{array}$ & $\begin{array}{l}\text { Warning sign with speed limit, marking of road } \\
\text { edge and centerline, removal of side obstacles, } \\
\text { painting beams and column of bridge rail. }\end{array}$ \\
\hline 148 & 0.9 & 5.7 & 7 & $\begin{array}{l}\text { High number of NMT, sharp curve after long tangent, } \\
\text { inappropriate coordination of horizontal and } \\
\text { vertical curves }\end{array}$ & $\begin{array}{l}\text { Warning sign with speed limit, text on road surface, } \\
\text { installation of rumble strips to reduce speed, } \\
\text { construction of painted guardrails. }\end{array}$ \\
\hline 142 & 0.75 & 4.8 & 8 & $\begin{array}{l}\text { Stopping and passing sight distance problem } \\
\text { and } 3 \text { pipe culverts per segment. }\end{array}$ & $\begin{array}{l}\text { Warning sign with recommended speed, } \\
\text { centerline and edge marking. }\end{array}$ \\
\hline Sum & 11.9 & 76.5 & & & \\
\hline
\end{tabular}

Frontage access especially two-access point located inside and outside of the curve and separated by less than $50 \mathrm{~m}$ distance.

Resulting, drivers (especially unfamiliar ones) may be surprised and may not be able to negotiate their speed in the tangent section and at the specified curved section of the road. This is also an indication of the chain effect of several road section characteristics and traffic related factors make road safety analysis a complex matter. As this study found, from this segment around 2.2 excess number of accidents expected to be encountered per year. On the other hand, equal amounts of accidents can be saved or benefited through implementation of appropriate countermeasures. Therefore, in order to mitigate such excess number of accidents per year this study recommends simple and cost effective engineering measures such as provision of warning sign with recommended speed, road 
surface marking, construction of painted guardrail outside the curve, installation of rumble strips to reduce speed and others as shown in Table 5 for this segment.

In similarly fashion, the major risk indicating factors for the occurrence of accidents and the proposed countermeasures for the top eight most dangerous road sites were provided in Table 5. Accordingly, this study found that after the implementation of the proposed remedial around 12 number of excess accidents can be reduced from the top 8 worst sites (which is equals to $12 \mathrm{~km}$ road segments) per year. This indicates the countermeasures benefits to save one accident per each kilometer of most dangerous road segments per year. Furthermore, this study recommends to implement some common countermeasures placed at logical locations consistently for all dangerous road segments such as road side signs with recommended speeds, pavement markings, text on road surface \& pedestrian crossing because they can provide an important information to improve road safety. This study propose that they need to be applied in a consistent way and to be placed at logical locations so as to be easy to understand and visible.

As per in-depth analysis of historical accidents, pedestrian collision were the most frequently occurred injury accident type and accounted around 44 per cent of injury accidents, which is unexpected result from rural roads. However, from field survey and in-depth investigation of traffic police report most of pedestrian collisions (more than 90 percent) occurred around village settlement, public area (such as School, Church, Mosque), at a place where access roads cross or join the road under investigation and also at narrow bridge location. Therefore, the provision of zebra crossing, posting reduced speed limit and installation of rumble strips can help to reduce speed at the specified places in order to reduce pedestrian collision.

Furthermore, from field survey and in-depth investigation of traffic police report non-motorized traffic, which is called animal drawn carts, usually share fast moving motor vehicle lanes. Accordingly, the involvement of animal drawn carts, usually Donkey drawn carts, was significant and accounted for more than 5 percent out of the total involved vehicles, which is greater than the involvements of automobiles. Most of these accidents occurred at nighttime due to the reason that animal drawn carts had not used any reflective materials. For that reason, motor vehicle drivers usually faced a problem to observe the carts within reasonable distance to stop their vehicles without colliding with them. Consequently, either motor vehicles usually collide with carts or they can be involved other types of accidents in order to save animal drawn carts. For instance, as traffic police reported, in order to avoid collision with animal drawn carts some driver took a decision like drive off the road or enter in to the opposing lane or try to stop the vehicle instantaneously. Due to these maneuver the vehicles had involved other types of accidents like roll over, collision with fixed objects, head on collision, rear end collision and turnover along the study area. In order to improve such accidents, segregating fast moving and slow moving traffics by 
constructing separate lanes for non-motorized traffic is very important. Equally, attention should be paid to enforce animal drawn carts to be equipped with reflective materials at the front and rear of the cart to improve visibility especially during nighttime.

\section{Conclusions}

Based on the selected method, out of 43 road segments, this study identifies 22 of them are singled out as dangerous road segments and ranked based on their excess number of expected accidents. The study also found that in total around 16 excess accidents can be expected from the identified 22 dangerous sites annually. Out of 22 ranked dangerous segments, eight of them are found to be the worst sites because they contributed around $76 \%$ of the total excess expected accidents frequencies. This study also found the major contributing road and traffic factors along the most dangerous segments include sharp horizontal curves after a long tangent, high number of non-motorized traffic and pedestrians directly access the road at a place where the road passes through village settlement, numbers of horizontal and vertical curves per $1.5 \mathrm{~km}$ road segment, poor coordination of horizontal and vertical alignments, terrain type, lane and/or shoulder width.

Accordingly, simple and cost effective countermeasures such as provision of warning sign with recommended speed, road surface marking, construction of painted guardrail outside the curve, provision of rumble strips, and others are proposed in order to reduce the excess number of accidents. Therefore, implementation of the identified countermeasures for the worst road segments especially those included in the first category of group rank will be vital to reduce the excess number of accidents.

\section{Limitation}

The severity of accidents were not considered in the analysis part of this study due to substantial amount of under-reporting of non-fatal injury accidents and the difficulties of estimating weight factor for each injury accidents to convert them into appropriate severity level as per local condition. In the accident prediction model the human and vehicle factors were not considered in this study, hence it will be good if further research will be geared to address the problem incorporating these factors.

\section{Acknowledgements}

The successful completion of this research was a result of many organizations and individuals. Accordingly, we sincerely acknowledge the following organizations for their assistant and corporation by providing the requested data for this paper: Ethiopian Road Authority, Federal Transport Authority, Federal Police Commission, Oromia Police Commission, West Arsi Zone Police Office and Arsi-Negele Woreda, Shashemene Woreda and Shashemene Town Traffic Police 
Offices. We also like to thank Mr. Edilu Shona and Mr. Shambel Demissie for their cross assistance and valuable comments through reading the draft manuscript of this paper. Finally, we would like to extend our special appreciation to Mr. Banteyidagn Abebayehu for his support during fieldwork by providing his car for data collection and site investigation work.

\section{References}

[1] United Nation Economic Commission for Africa (2009) Case Study Report on Road Safety in Ethiopia.

[2] Ethiopian Road Authority (ERA) (2004) Road Safety Audit Manual. Federal Democratic Republic of Ethiopia, Addis Ababa.

[3] World Health Organization (2009) Global Status Report on Road Safety Time for Action Geneva. http://www.who.int/violence_injury_prevention/road_safety_status/2009/en/

[4] World Health Organization (2015) Global Status Report on Road Safety. http://www.who.int/violence_injury_prevention/road_safety_status/2015/en/

[5] TRL (2001) Ross Silcock Partnership, Study Report for a Sectoral Road Safety Program in Ethiopia. Volume 1, Transport Research Laboratory, Addis Ababa.

[6] Berhanu, G. (2000) Effects of Road and Traffic Factors on Road Safety in Ethiopia. Norwegian University of Science and Technology, Trondheim.

[7] Segni, G. (2007) Causes of Road Traffic Accidents and Possible Counter Measures on Addis Ababa-Shashemene Road. Master's Thesis, Addis Ababa University, Addis Ababa.

[8] Elvik, R. (2008) The Predictive Validity of Empirical Bayes Estimates of Road Safety. Accident Analysis \& Prevention. https://doi.org/10.1016/j.aap.2008.07.007

[9] Hauer, E. (1986) On the Estimation of the Expected Number of Accidents. Accident Analysis \& Prevention 18, 1-12.

[10] Stokes, R.W. and Mutabazi, M.I. (1996) Rate-Quality Controls Method of Identifying Hazardous Road Locations. Transport Research Record, 1542, 44-48.

[11] McGuigan, D.R.D. (1981) The Use of Relationship between Road Accident and Traffic Flow in Black-Spot Identification. Traffic Engineering and Control, 22, 448-453.

[12] Maher, M.J. and Mountain, L.J. (1988) The Identification of Accident Black Spots: A Comparison of Current Methods. Accident Analysis and Prevention, 20, 143-151.

[13] Hauer, E. (1997) Observational Before-After Studies in Road Safety. Pergamon Publications, London.

[14] American Association of State Highway and Transportation Officials (AASHTO) (2009) Highway Safety Manual.

[15] PIARC (2003) Road Safety Manual. World Roads Association.

[16] Persaud, B., Lyon, G. and Nguyen, T. (1999) Empirical Bayes Procedure for Ranking Sites for Safety Investigation by Potential for Safety Improvement. Transportation Research Record, 1665, 7-12. https://doi.org/10.3141/1665-02

[17] Saccomanno, F.F., Grossi, R., Greco, D. and Mehmood, A. (2001) Identifying Black Spots along Highway SS107 in Southern Italy using Two Models. Journal of Transportation Engineering, 6, 551-521.

[18] Carlin, B.P. and Louis, T.A. (1997) Bayes and Empirical Bayes Methods for Data 
Analysis. Statistics and Computing, 7, 153-154.

[19] Cheng, W. and Washington, S.P. (2005) Experimental Evaluation of Hotspot Identification Methods. Accident Analysis \& Prevention, 37, 870-881.

[20] Directive 2008/96/Ecof, The European Parliament and of the Council of 19 November 2008 on Road Infrastructure Safety Management.

[21] Hauer, E. (1992) Empirical Bayes Approach to the Estimation of Unsafely-The Multivariate Regression Method. Accident Analysis \& Prevention, 24, 457-477.

[22] Hauer, E., Harwood, D.W., Council, F.M. and Griffith, M.S. (2002) Estimating Safety by the Empirical Bayes Method: A Tutorial. Transportation Research Record: Journal of the Research Board, No. 1784, 126-131.

[23] Hauer, E., Persaud, B.N., Smiley, A. and Duncan, D. (1991) Estimating the Accident Potential of an Ontario Driver. Accident Analysis \& Prevention, 23, 133-152.

[24] Tunaru, R. (2002) Hierarchical Bayesian Models for Multiple Count Data. Austrian Journal of Statistics, 31, 221-229.

[25] Ethiopian Road Authority (ERA) (2001) Geometric Design Manual. Federal Democratic Republic of Ethiopia, Addis Ababa.

[26] Dissanayeke, S. and Ratnayake, I. (2006) Statistical Modeling of Crash Frequency on Rural Freeways and Two-Lane Highways using Negative Binomial Distribution. Advance in Transportation Studies an International Journal, 8 Section B 9.

[27] Miaou, S.-P. (1996) Measuring the Goodness-of-Fit of Accident Prediction Models. FHWA-RD-96-040, Federal Highway Administration, Washington DC.

[28] Wood, G.R. (2002) Generalized Linear Accident Models and Goodness-of-Fit Testing. Accident Analysis \& Prevention, 34, 417.

https://doi.org/10.1016/S0001-4575(01)00037-9 